\title{
The Incidence of Child Abuse in Serial Killers
}

\author{
Heather Mitchell and Michael G. Aamodt \\ Radford University
}

Fifty serial killers who murdered for the primary goal of attaining sexual gratification, termed lust killers, were studied to determine the prevalence of childhood abuse. Information regarding the childhood abuse sustained by each killer was obtained primarily from biographical books, newspaper articles, and online sites. Abuse was categorized into physical abuse, sexual abuse, psychological abuse, and neglect and was then compared to societal norms from 2001. Abuse of all types excluding neglect was significantly higher in the serial killer population. For serial killers, the prevalence of physical abuse was 36\%; sexual abuse was 26\%; and psychological abuse was 50\%. Neglect was equally prevalent in the serial killer (18\%) and societal norm populations.

A

SERIAL KILLER is defined as a person who murders three or separate events, with a "cooling off period” between kills (Egger, 2002; Hickey, 2002; Ressler \& Shachtman, 1992). Serial killers have a type of cycle during which they kill, presumably during some period of stress. After the cathartic experience is accomplished, they feel temporarily relieved of this pressure. Although the exact number of serial killers through history is unknown, estimates range as high as 1,500 serial killers (Newton, 2000).

A commonly asked question is why these incidents occur. The great interest in this question is due in part to the large number of serial killers and in part to the heinous nature of these crimes. Finding a reason that a person would engage in committing multiple murders has brought suggestions involving many facets of the perpetrator's life (Pincus, 2001; Ressler \& Shachtman, 1992). Possible biological contributions include head injury involving brain damage, brain anomalies, and faulty genetics. Familial contributions include the physical absence or lack of personal involvement by one or both parents and alcohol or drug dependency by one or both parents.

Perhaps one of the most interesting factors contributing to the development of a serial killer is abuse that is experienced in the killer's childhood. Childhood abuse has been given varying levels of blame in the development of serial killers. De Becker (1997) quoted Ressler's research and stated that "100 percent [of serial killers] had been abused as children, either with violence, neglect, or humiliation" (p. 55). Ressler and Shachtman (1992) report that, "over 40 percent of the [serial] murderers reported being physically beaten and abused in their childhoods. More than 70 percent said they had witnessed or been part of sexually stressful events when young...” (p. 85). With such variance in estimates and with the prevalence of childhood abuse reported much higher than in the 
normal population, a closer examination of the topic seems prudent.

\section{Definition of Abuse}

Abuse connotes variances in public opinion, so a working definition is required for each subtype. All definitions used in this research were derived from the Virginia Department of Social Services (2003); however, in some cases, they were expanded to include other incidents of maltreatment. All of these categories apply to abuse occurring when the child is under the age of 18.

Physical abuse is defined as causing or allowing any nonaccidental physical injury. For instance, the mother of child rapist and murderer Lorenzo Fayne had to be counseled by social services not to strike her son in the head as punishment (Goodrich, 1994; Malone, 2000).

Sexual abuse is defined as any sexual activity, practice or instruction which either meets the criminal definition or is unhealthy for a child considering his/her age and level of development. Criminal activity is defined as "commit[ting] or allow[ing] to be committed any illegal sexual act upon a child including incest, rape, fondling, indecent exposure, prostitution, or allow[ing] a child to be used in any sexually explicit visual material." For example, serial killer Bobby Joe Long was forced to sleep in the same bed with his mother until he was 13 years old and was forced to watch her have sex with men (Flowers, 2000).

Psychological abuse refers to any acts such as intentional humiliation, causing emotional conflict, or any act that could be psychologically damaging to the child, such as dressing a boy like a girl. Such was the case with serial killer Carroll Edward Cole. His mother, aware of his anger at being teased by other children regarding his "feminine name," dressed him in girl's clothing and forced him to serve tea to neighborhood ladies (Newton, 1994; Newton, 2000).

Neglect is defined as failing or refusing to provide adequate food, clothing, shelter, emotional nurturing, or health care. It may also mean failing to provide adequate supervision in relation to the child's age and level of development. For example, serial killer Carlton Gary reportedly was forced to eat out of trash bins at times because his mother would forget to feed him (Jury indicts Georgian, 1984).

Another category for abuse-“other"records forms of maltreatment not specifically fitting in the first three categories. In the Code of Virginia this term applies to threatening to cause a physical injury, abandoning a child, and drug addiction while in utero. This category was not used for the present research due to inconsistent reporting in the literature.

\section{Types of serial killers}

Because killers ply their trade for various reasons, it is necessary to distinguish among the types of killers and the underlying motive for their kills. These motives may include the obtaining of money, the experience of the thrill, the sense of power, and the desire to rid the world of evil doers, among other reasons (Egger, 2002; Hickey, 2002).

Although other motivations for killing exist, this study will focus on Lust Killers, those who kill for some sexual gratification (Egger, 2002; Hickey, 2002). Lust killers may engage in sex with someone and kill them to prevent leaving a witness, as was the practice of serial killer Glen Rogers (Linedecker, 1997). For serial killers such as Kendall Francois (Rosen, 2002), sexual climax is not possible without killing their partner. Or the killing may be a gateway to the ac- 
tual sex act, preferring a dead body to a live partner, as was the case with Jeffrey Dahmer (Davis, 1995).

\section{METHOD}

Obtaining accurate information on the individuals in this research was an arduous process. Determining which persons were eligible for inclusion in this research was begun using Appendix A in Michael Newton's (2000) The Encyclopedia of Serial Killers, which categorizes offenders according to their motivations for murder. Those labeled as having a motive of lust were considered for this research project. To make eventual comparisons between abuse levels of serial killers and normative abuse levels, only lust killers who were born and educated in the United States were considered. In instances when competing motivations existed or when the lust killing motivation could not be justified by this author, those particular offenders were eliminated from the research. A list of 77 possible offenders was generated; however, valid information pertaining to the childhood experiences could be found for 50 .

Information for each serial killer was obtained through many sources, including books listed in a bibliography of serial killers (Aamodt \& Moyse, 2003), the Internet, newspaper articles, and personal communication. For each person included, at least three credible sources of information were required. Biographical books or excerpts of passages containing such data (i.e., psychiatrist-related reports) were used. Forty-eight books were used for this research.

Several websites that compile information specifically about serial killers were visited, such as www.angelfire.com, www.darkday.tripod.com, www. mayhem.net, and www.crimelibrary.com. In all, information was retrieved from 54 such websites. Newspaper articles were collected from the online news databases Factiva and Lexis-Nexis. Data were used from 140 news stories.

Although these sources provided considerable useful information, some provided conflicting or non-specific information. In these three instances, the author contacted the offenders directly by writing to them in prison. Two offenders wrote back, contributing their versions of their biographies. One of these killers, Arthur Shawcross, disclosed extreme abuse that could not otherwise be confirmed. His report was considered unfounded and therefore, was not included.

Finally, the data retrieved from these sources were compared to societal norms. Readers interested in examining the sources used for each serial killer can obtain the complete reference section at www.radford.edu/ maamodt/abuse.htm.

\section{RESULTS}

For the 50 serial killers, the following breakdown of abuse was found:

- Some type of maltreatment, regardless of abuse type (68\%)

- Physical abuse (36\%)

- Sexual abuse (26\%)

- Psychological abuse (50\%)

- Neglect (18\%)

- No abuse (32\%)

In addition to studying the abuse suffered by each of these lust killers, a closer examination of the subtypes was done. Lust killers are typically divided into organized, disorganized, and mixed offenders (Hickey, 2002; Ressler \& Shachtman, 1992).

Organized offenders tend to plan many elements of their attacks (Hickey, 2002; Ressler \& Shachtman, 1992). They 
choose victims who are at a low risk of being victims, tend to bring weapons with them, and remove the weapons from the scene to help prevent identification. Organized offenders, acting out a wellplayed fantasy, wish to complete a preconceived sex act, and they are usually successful at completing the act. Once their fantasy acts are completed, they tend to end the victim's suffering quickly and then dispose of the body to prevent detection.

After the actual sex-murder is complete, organized offenders will likely follow the news to check the status of the investigation (Hickey, 2002; Ressler \& Shachtman, 1992). They may even go to the police offering any assistance they can provide without disclosing their true involvement. They may also gain excitement from reliving the crime and may take trophies from their conquests to assist with this experience.

In contrast to organized offenders, disorganized offenders are not as "cautious" (Hickey, 2002; Ressler \& Shachtman, 1992). They generally have some mental defect that prevents planning ability. Whereas organized offenders usually target strangers who fit into some criteria, disorganized offenders are opportunists; their victims tend to be the result of the occasion at hand. They tend to choose people who are already at risk of becoming victims (e.g., prostitutes), thereby lessening the effort they put forth. They tend to use weapons found at the scene and are not generally careful to dispose of them after the murder act is complete. Disorganized offenders will engage in a sex act, but they will generally be unable to complete the act. They may disfigure a person or remove a body part, but they are otherwise unconcerned with the body postmortem (or after all sex acts are completed).

A third type of offender is the mixed offender (Hickey, 2002; Ressler \& Shachtman, 1992). The mixed offender displays aspects of both the organized and disorganized offenders, characteristics that normally are not found together. The offender types for the serial killers used in this study are located in Appen$\operatorname{dix}$ A.

As shown in Table 1, no substantial difference in the frequency of abuse among the various types of serial killers was found.

To better understand the prevalence of abuse among serial killers, the prevalence among the general population must be examined. As shown in Table 2, the prevalence of abuse in serial killers is clearly greater than the population in general.

Table 1: Comparison of organized and disorganized serial killers

\begin{tabular}{lccc}
\hline \multirow{2}{*}{ Type of Abuse } & \multicolumn{3}{c}{ Type of Killer } \\
\cline { 2 - 4 } & $\begin{array}{c}\text { Organized } \\
(\mathrm{n}=25)\end{array}$ & $\begin{array}{c}\text { Disorganized } \\
(\mathrm{n}=11)\end{array}$ & $\begin{array}{c}\text { Mixed } \\
(\mathrm{n}=14)\end{array}$ \\
\hline Maltreated (Regardless of type) & $68 \%$ & $64 \%$ & $72 \%$ \\
& & & $36 \%$ \\
Physical & $36 \%$ & $36 \%$ & $21 \%$ \\
Sexual & $24 \%$ & $36 \%$ & $43 \%$ \\
Psychological & $52 \%$ & $27 \%$ & $29 \%$ \\
Neglect & $16 \%$ & $36 \%$ & \\
\hline
\end{tabular}


Table 2: Comparison of serial killers to the general population

\begin{tabular}{lll}
\hline Type of Abuse & $\begin{array}{l}\text { General } \\
\text { Popula- } \\
\text { tion }\end{array}$ & $\begin{array}{l}\text { Serial } \\
\text { Killer } \\
\text { Popula- } \\
\text { tion }\end{array}$ \\
\hline Physical & $6 \%$ & $36 \%$ \\
Sexual & $3 \%$ & $26 \%$ \\
Psychological & $2 \%$ & $50 \%$ \\
Neglect & $18 \%$ & $18 \%$ \\
Other & $6 \%$ & $\mathrm{~N} / \mathrm{A}$ \\
No Abuse Reported & $70 \%$ & $32 \%$ \\
\hline
\end{tabular}

Upon reviewing both sets of data, we are able to detect many differences between the amount and types of maltreatment in the studied serial killers compared with the general population. The first difference lies in the realm of physical abuse. The general population reported a proportion of $6 \%$ in the year 2001 (Childhelp USA, 2002). The serial killers had an overall proportion of 36\%, six times that of society in general. That frequency of physical abuse was consistent regardless of the type of killer.

Serial killers were far more likely to have been sexually abused as children than was the population in general. Compared with the societal proportion of $3 \%, 26 \%$ of the serial killers studied were sexually abused - a rate almost nine times that found in the general population. Disorganized offenders were the most likely of the three types to have suffered some form of sexual abuse.

Psychological abuse equated to $2 \%$ in the general population as opposed to $50 \%$ in the sample population. This is the most glaring difference so far. Organized offenders were the most likely of the three types to have experienced such and disorganized offenders were the least likely.

The final category, neglect, seems greatly underrepresented in this study. Eighteen percent of the general popula- tion's children were neglected in childhood. For serial killers, this proportion was the same. Organized offenders only saw neglect $16 \%$ of the time; whereas disorganized offenders saw it 33\% of the time.

\section{CONCLUSION}

Contrasting the data obtained from this research with the rates of childhood abuse in the general population yields striking findings. Child abuse is clearly more prevalent in the population of lust serial killers than it is in society in general. With the exception of neglect, which demonstrated equal rates in both populations, the proportion found in the lust killers was considerably higher than the normal United States population.

It is commonly known that incidents of childhood abuse frequently go unreported. Therefore, the rates reported are probably not an accurate depiction of actual abuse sustained. In fact, the proportions reported by the Administration for Children and Families (2001) are based on substantiated reports by social services and child protective services personnel.

Collecting data pertaining to the lust serial killers posed some problems as well. This type of research has some problems that cannot be readily overcome. One problem is that the vast majority of information received is from an uninvolved third party. The truthfulness of this information must be questioned at times. Also, the perpetrators of crimes will frequently report incidents in which they were mistreated. They do this to offer an explanation for their subsequent wrongdoings or to seek clemency. Some of these claims cannot be corroborated.

Another potential fallacy in the reporting of maltreatment by serial killers is 
that it may be underreported. Some hardened criminals do not wish to divulge any facet of their lives which may cause them to be vulnerable. Others do not consider that treatment they received as children to be abusive; they may consider it to be commonplace and characteristic for their generation and their region. Some may realize that they have been abused but do not wish to communicate this out of protection for their parents, siblings, or other loved ones.

With these considerations in mind, the prevalence of childhood abuse found among lust serial killers could be counted as a contributing factor toward creating a dysfunctional way of dealing with others, consistent with the punishment that they doled out to others. Since a portion of the murderers experienced no abuse, it may not be considered as the sole contributing factor or causal agent. Although researchers may never know all of the contributing factors for the development of serial killers, abuse must be considered.

Though the prevalence of abuse in the childhoods of the serial killers in this study was certainly higher than that found in the general population, caution is warranted in generalizing these findings to all serial killers. The serial killers included in this study were lust killers whose crimes generated enough interest with the general public that they were covered extensively in media articles, true crime books, and web sites. The prevalence of abuse in the childhoods of other types of serial killers (e.g., black widows, visionaries, thrill killers) might be different.

Likewise, the prevalence of abuse in serial killers not receiving extensive public attention might be different as well. Further research utilizing persons from the various categories of serial killers and other variables — such as brain injury or anomalies, among the many possible variables-is needed.

\section{REFERENCES}

Aamodt, M. G., \& Moyse, C. (2003). Researching the multiple murderer: A comprehensive bibliography of books on specific serial, mass, and spree killers. Journal of Police and Criminal Psychology, 18(1), 61-85.

Administration for Children and Families (2001). Victims. Child Maltreatment (chap. 3). Retrieved April 15, 2003, from http://www.acf.dhhs.gov/programs/cb/public ations/cm01/chapterthree.htm

Childhelp USA. National child abuse statistics (2002, June). Retrieved April 15, 2003, from http://www.happinessonline.org/LoveAndHe lpChildren/p6.htm

Davis, D. (1995). The Milwaukee murders: Nightmare in apartment 213. NY: St. Martins Paperbacks.

De Becker, G. (1997). The gift of fear. NY: Dell Publishing.

Egger, S. A. (2002). The killers among us $\left(2^{\text {nd }}\right.$ ed.). Upper Saddle River, New Jersey: Prentice Hall.

Flowers, A. (2000). Bound to die: The shocking true story of Bobby Joe Long, America's most savage serial killer. NY: Pinnacle Books.

Goodrich, R. (1994, August 17). Fayne guilty of murder; four more cases remain. St. Louis Post-Dispatch. Retrieved March 13, 2003, from the Lexis-Nexis database.

Hickey, E. W. (2002). Serial murderers and their victims ( $3^{\text {rd }}$ ed.). Belmont: Wadsworth.

Jury indicts Georgian as 'Stocking Strangler'. (1984, May 5). The New York Times. Retrieved March 13, 2003, from the LexisNexis database.

Linedecker, C. L. (1997). Smooth operator: The true story of accused serial killer Glen Rogers. NY: St. Martins Press.

Malone, R. (2000, March 12). Murderous 'recipe' was there for Fayne, his attorney says; His childhood was marred by violence, criminal behavior; the killer. St. Louis PostDispatch. Retrieved March 13, 2003, from the Lexis-Nexis database.

Newton, M. (1994). Silent rage: Inside the mind of a serial killer. NY: Dell Publishing. 
Newton, M. (2000). The encyclopedia of serial killers. NY: Checkmark Books.

Pincus, J. H. (2001). Base instincts: What makes killers kill? NY: W. W. Norton \& Co.

Ressler, R. K. \& Shachtman, T. (1992). Whoever fights monsters. NY: St. Martins Press.

Rosen, F. (2002). Body dump. NY: Pinnacle.

Sexual Abuse Statistics (n.d.). Pandora's Box. Retrieved April 14, 2003, from http://www.prevent-abusenow.com/stats.htm

Virginia Department of Social Services (2003). Virginia cares about children and their fami- lies: A guide to child protective services. [Brochure]

www.angelfire.com

www.darkday.tripod.com

www.mayhem.net

www.crimelibrary.com

Authors' Note: Communications may be addressed to Michael G. Aamodt, Ph.D., Department of Psychology, Radford University, Radford, VA 24142, maamodt@radford.edu 
Appendix A: Abuse Experienced by Each Serial Killer

\begin{tabular}{|c|c|c|c|c|c|}
\hline Name & $\begin{array}{l}\text { Organized/ } \\
\text { Disorganized }\end{array}$ & $\begin{array}{l}\text { Physical } \\
\text { Abuse }\end{array}$ & $\begin{array}{l}\text { Sexual } \\
\text { Abuse }\end{array}$ & $\begin{array}{l}\text { Psychological } \\
\text { Abuse }\end{array}$ & Neglect \\
\hline Charles Albright & Organized & No & No & Yes & No \\
\hline Cesar Barone & Organized & No & No & No & No \\
\hline Herbert Baumeister & Disorganized & Yes & No & Yes & No \\
\hline Arthur Bishop & Mixed & No & No & No & No \\
\hline Lawrence Bishop & Organized & No & No & No & No \\
\hline William Bonin & Organized & Yes & Yes & No & Yes \\
\hline David Carpenter & Mixed & Yes & No & Yes & No \\
\hline Douglas Clark & Organized & No & No & No & No \\
\hline Carroll Edward Cole & Organized & Yes & No & Yes & Yes \\
\hline Dean Corll & Disorganized & No & No & Yes & No \\
\hline Jeffrey Dahmer & Disorganized & No & Yes & No & No \\
\hline Wesley Allen Dodd & Organized & Yes & No & Yes & Yes \\
\hline Larry Eyler & Organized & Yes & No & Yes & No \\
\hline Lorenzo Fayne & Disorganized & Yes & Yes & Yes & Yes \\
\hline Kendall Francois & Disorganized & No & No & No & No \\
\hline John Wayne Gacy & Organized & Yes & Yes & Yes & No \\
\hline Gerald Gallego & Organized & No & No & Yes & No \\
\hline Carlton Gary & Disorganized & Yes & No & Yes & Yes \\
\hline Donald Gaskins, Jr. & Mixed & Yes & Yes & Yes & No \\
\hline Harvey Glatman & Organized & No & No & No & No \\
\hline Robert Hansen & Mixed & No & No & Yes & No \\
\hline Charles Hatcher & Mixed & Yes & No & No & No \\
\hline Gary Heidnik & Mixed & Yes & No & Yes & Yes \\
\hline Edmun Kemper, III & Mixed & No & No & Yes & No \\
\hline Randy Kraft & Organized & No & No & No & No \\
\hline Lewis Lent, Jr. & Mixed & No & Yes & Yes & No \\
\hline Bobby Joe Long & Mixed & No & Yes & Yes & No \\
\hline Kenneth McDuff & Mixed & No & No & No & No \\
\hline Wayne Nance & Organized & No & No & Yes & No \\
\hline Eric Napoletano & Organized & No & Yes & No & Yes \\
\hline Darren O’Neall & Organized & No & No & No & No \\
\hline Carl Panzram & Disorganized & Yes & Yes & No & Yes \\
\hline Charles Rathbun & Mixed & No & No & No & No \\
\hline Robert Ben Rhoades & Organized & No & No & No & No \\
\hline Joel Rifkin & Organized & No & No & No & No \\
\hline Glen Rogers & Organized & No & No & Yes & No \\
\hline Danny Rolling & Mixed & Yes & No & Yes & No \\
\hline Michael Ross & Organized & Yes & Yes & Yes & No \\
\hline George Russell, Jr. & Mixed & No & No & No & Yes \\
\hline Gerald Schaefer & Organized & No & No & Yes & No \\
\hline Arthur Shawcross & Disorganized & No & No & No & No \\
\hline Timothy Spencer & Disorganized & No & No & No & No \\
\hline William Suff & Organized & No & No & Yes & No \\
\hline Henry Wallace & Organized & Yes & Yes & No & No \\
\hline Faryion Wardrip & Disorganized & No & No & No & No \\
\hline Leslie Warren & Organized & Yes & No & Yes & No \\
\hline James Wood & Disorganized & No & Yes & No & No \\
\hline Randall Woodfield & Mixed & No & No & No & No \\
\hline Robert Yates, Jr. & Organized & No & Yes & No & No \\
\hline Charles Yukl & Organized & Yes & No & Yes & No \\
\hline
\end{tabular}

